\title{
INFLUÊNCIA DA ESCÓRIA SILICATADA NA ACIDEZ DO SOLO E NA PRODUTIVIDADE DE GRÃOS DO ARROZ DE TERRAS ALTAS
}

\author{
Influence of calcium silicate slag on soil acidity and upland rice grain yield
}

\author{
Morel Pereira Barbosa Filho ${ }^{1}$, Francisco José Pfeilsticker Zimmermann², Osmira Fátima da Silva ${ }^{3}$
}

\begin{abstract}
RESUMO
Apesar dos elevados teores de $\mathrm{SiO}_{2}$ total geralmente encontrados nos solos brasileiros, o teor na solução do solo pode ser baixo, em consequiência do processo de dessilicificação que ocorre durante a intemperização dos solos. A aplicação de escórias de processamento industrial, ricas em silicatos de cálcio, tem mostrado efeitos positivos quanto à ação corretiva da acidez do solo e ao fornecimento de Si às plantas acumuladoras desse elemento, com aumentos significativos de produtividade. Conduziuse este trabalho com o seguinte objetivo: avaliar em dois anos de cultivo sucessivos a ação corretiva, a produtividade de grãos e a absorção de Si pelo arroz de terras altas. Foram aplicadas ao solo de cerrado classificado como latossolo vermelho distroférrico de cerrado seis doses $\left(0,2,4,6,8\right.$ e $\left.10 \mathrm{t} \mathrm{ha}^{-1}\right)$ de uma escória silicatada com $20 \%$ de $\mathrm{SiO}_{2}$ total, proveniente do processo de fabricação de superfosfatos em forno elétrico. Utilizou-se o delineamento de blocos completos casualizados com cinco repetições. Foram detectados aumentos significativos de produtividade de grãos, teor e acumulação de Si na palha e da porcentagem de grãos cheios por panícula, nos dois anos de cultivo do arroz. Houve ação corretiva no solo das doses de escória, reduzindo a acidez e aumentando a disponibilidade de $\mathrm{P}, \mathrm{Si}$, Ca trocável e a porcentagem de saturação por bases. O nível crítico de Si na palha por ocasião da colheita, para obtenção de produtividade satisfatória de grãos, foi estabelecido em $2,25 \mathrm{~g} \mathrm{~kg}^{-1}$ de matéria seca.
\end{abstract}

Termos para indexação: Oryza sativa L., solos de cerrado, extratores, silício, corretivo de solo.

\begin{abstract}
Despite the high $\mathrm{SiO}_{2}$ total content often found in Brazilian soils, the soluble silicon content in soil solution can be low due to weathering that occur in soils. The application of calcium silicate slags, under these conditions, has demonstrated positive effects in relation to correction of soil acidity, the supply of Si to plants that accumulate this element and significant yield increase. The objectives of this investigation were to evaluate in two consecutive years, soil acidity correction, grain yield and $\mathrm{Si}$ uptake in upland rice. Six doses of calcium silicate slag with $20 \%$ of total $\mathrm{SiO}_{2}\left(0,2,4,6,8\right.$ and $\left.10 \mathrm{t} \mathrm{ha}^{-1}\right)$ in form of calcium silicate slag, a subproduct of phosphorus processed in electric furnace was applied to oxisoil. The experimental design was a randomized complete block with five repetitions. Application of calcium silicate slag resulted in significant grain yield increase, tissue silicon content and silicon accumulation in straw and the filled grain percentage in the first and in the second year of rice cultivation. The critical Si level in the rice straw required for obtaining satisfactory yield was $2,25 \mathrm{~g} \mathrm{~kg}^{-1}$ of dry matter. In soil, the application of calcium silicate slag reduced soil acidity and increased available $\mathrm{P}, \mathrm{Si}$, exchangeable $\mathrm{Ca}$, and saturation of bases. There was significant correlation between soluble $\mathrm{Si}$ extracted in acetic acid extraction $0.5 \mathrm{~mol} \mathrm{~L}^{-1}$ and water, in relation to soluble Si content found in soil after rice cultivation.
\end{abstract}

Index terms: Oryza sativa L., Savanna soils, extractants, silicon, soil amendment.

(Recebido para publicação em 30 de junho de 2003 e aprovado em 4 de dezembro de 2003)

\section{INTRODUÇÃO}

As escórias silicatadas são usadas no cultivo do arroz em várias partes do mundo. Os propósitos são neutralizar a acidez do solo e reduzir os efeitos prejudiciais causados por patógenos, especialmente a brusone, causada por Piricularia grisea (DATNOFF et al., 1991, 1992; CORREA-VICTORIA et al., 1996; PRABHU et al., 1996, 1999). No Brasil, onde o arroz de terras altas é predominantemente cultivado, além do efeito benéfico sobre severidade de brusone (PRABHU et al., 1996, 1999), os corretivos à base de silicatos têm mostrado também efeitos positivos na correção da acidez do solo, no aumento da disponibilidade de $\mathrm{Ca}$, Si e $\mathrm{P}$ e na produtividade de grãos (KORNDÖRFER et al., 1999; BARBOSA FILHO et al., 2001b).

1. Pesquisador, Dr., Embrapa Arroz e Feijão, Caixa Postal 179, 75375-000 - Santo Antônio de Goiás, GO. morel@cnpaf.embrapa.br

2. Pesquisador, Ph.D., Embrapa Arroz e Feijão. fjpz@cnpaf.embrapa.br

3. Economista, Embrapa Arroz e Feijão. osmira@cnpaf.embrapa.br 
O Si é o elemento absorvido em maior quantidade pelo arroz, cerca de duas vezes mais que o potássio (IFA, 1992; SAVANT et al., 1997). Em alguns países asiáticos, como Japão e Taiwan, utilizam, anualmente, de 1,5 a 2,0 t ha ${ }^{-1}$ de escórias, visando, além de corrigir a acidez do solo, favorecer o acúmulo de Si nas plantas de arroz irrigado. Com isso, aumentos significativos de produtividade de grãos têm sido obtidos (LIAN, 1976). No Brasil, a cultura do arroz de terras altas pode também responder à aplicação de silicatos, dependendo da disponibilidade de Si nos solos. Análise de Si disponível em algumas áreas de arroz irrigado do Estado do Tocantins indicaram teores em ácido acético $0,5 \mathrm{~mol} \mathrm{~L}^{-1}$, variando de 8,8 a $66,4 \mathrm{mg} \mathrm{litro}^{-1}$, com média de $31,5 \mathrm{mg} \mathrm{L}^{-1}$ (dados não publicados). Em um latossolo vermelho distroférrico, Barbosa Filho et al. (2001b) encontraram $13 \mathrm{mg} \mathrm{dm}^{-3}$ de Si solúvel em ácido acético $0,5 \mathrm{~mol}$. Utilizando o mesmo extrator, Korndörfer et al. (1999) estabeleceram o nível de suficiência de Si disponível no solo para o arroz de terras altas em $9,8 \mathrm{mg} \mathrm{dm}^{-3}$.

Entre os produtos utilizados na correção da acidez do solo, os mais comuns são os carbonatos de Ca e $\mathrm{Mg}$, mais conhecidos como calcários. Entretanto, as escórias de composição silicatada podem constituir uma outra fonte alternativa de correção de acidez, mais vantajosa para a cultura do arroz, comparativamente aos calcários, pois, além de neutralizarem a acidez, os íons solúveis de silicato liberados durante o processo de dissolução no solo são fixados pelas partículas do solo (óxidos e hidróxidos de $\mathrm{Fe}$ e $\mathrm{Al}$ ), competindo com íons fosfatos pelos mesmos sítios de troca, com conseqüente aumento da disponibilidade de fósforo na solução do solo (ROY et al., 1971; SNYDER et al., 1986; SOUZA e YASUDA, 1994).

No Brasil, foram cultivados, na safra de 2001/2002, 3,15 milhões de hectares de arroz, sendo $58 \%$ dessa área ocupada por arroz de terras altas, com rendimento médio de $1.743 \mathrm{~kg} \mathrm{ha}^{-1}$, segundo Levantamento Sistemático da Produção Agrícola do IBGE (2002). Entre os fatores responsáveis por essa baixa produtividade, destacam-se a acidez dos solos, a baixa saturação por bases e a alta capacidade de fixação de fósforo. Nessas condições, as escórias silicatadas, além de atuarem como corretivo de acidez do solo, podem ser importantes como fontes de Si para as plantas de arroz. Estudos sobre o potencial das escórias provenientes do processamento industrial para uso no cultivo do arroz no Brasil não têm sido suficientemente avaliados como em outros países.
Realizou-se este trabalho com o objetivo de avaliar os efeitos de doses de uma escória proveniente do processamento da fabricação de superfosfatos, rica em Si, sobre a correção da acidez, absorção de Si e produtividade de grãos de arroz de terras altas, em um latossolo vermelho distroférrico de cerrado.

\section{MATERIAL E MÉTODOS}

O experimento foi conduzido em área experimental localizada no município de Santo Antônio de Goiás, GO, Lat.:16 28' 00", Long.: 49 17' 00" e Alt.: $823 \mathrm{~m}$, pertencente à Embrapa Arroz e Feijão. O solo é caracterizado como latossolo vermelho distroférrico textura franco argilosa, com baixos teores de matéria orgânica e P disponível pelo extrator de Mehlich-1 de $2,7 \mathrm{mg} \mathrm{dm}^{-3}$ de solo, com $30 \%$ de saturação por bases na camada superficial. As amostras de solo coletadas na camada de 0-20 cm de profundidade antes do plantio foram analisadas quimicamente, segundo metodologia descrita por EMBRAPA (1997), revelando os seguintes resultados: $\mathrm{pH}$ em $\mathrm{H}_{2} \mathrm{O}(1: 2,5)=5,6$; matéria orgânica $=$ $18 \mathrm{~g} \mathrm{~kg}^{-1} ; \mathrm{P}$ disponível em Mehlich-1 = 2,7 mg dm${ }^{-3} ; \mathrm{K}$ trocável $=2,2 \mathrm{mmol}_{\mathrm{c}} \mathrm{dm}^{-3} ;$ Ca trocável $=16 \mathrm{mmol}_{\mathrm{c}} \mathrm{dm}^{-}$ ${ }^{3} ; \mathrm{Mg}$ trocável $=10 \mathrm{mmol}_{\mathrm{c}} \mathrm{dm}^{-3} ; \mathrm{Al}$ trocável extraído em $\mathrm{KCl} 1 \mathrm{~mol} \mathrm{~L}^{-1}=0,1 \mathrm{mmol}_{\mathrm{c}} \mathrm{dm}^{-3} \mathrm{e} \mathrm{H}+\mathrm{Al}=6,5 \mathrm{mmol}_{\mathrm{c}}$ $\mathrm{dm}^{-3}$; $\mathrm{Cu}$ disponível em Mehlich-1 = $23 \mathrm{~g} \mathrm{~kg}^{-1}$; Mn disponível em Mehlich-1 = $230 \mathrm{~g} \mathrm{~kg}^{-1}$; Fe disponível em Mehlich-1 = $420 \mathrm{~g} \mathrm{~kg}^{-1}$; Zn disponível em Mehlich-1 $=21 \mathrm{~g} \mathrm{~kg}^{-1}$; soma de bases $=28,2 \mathrm{mmol}_{\mathrm{c}} \mathrm{dm}^{-3} ; \mathrm{T}=93,2 \mathrm{mmol}_{\mathrm{c}} \mathrm{dm}^{-3} \mathrm{e} \mathrm{V}=30 \%$. O Si solúvel foi extraído em ácido acético $0,5 \mathrm{~mol} \mathrm{~L}^{-1} \mathrm{e}$ determinado colorimetricamente usando o complexo de molibdato de amônio (SNYDER, 1991) cuja concentração foi de $16 \mathrm{mg} \mathrm{L}^{-1}$.

Os tratamentos consistiram da aplicação de doses $\left(0,2,4,6,8\right.$ e $\left.10 \mathrm{t} \mathrm{ha}^{-1}\right)$ de escória com $20 \%$ de $\mathrm{SiO}_{2}$ total, originada do processamento industrial de fabricação de superfosfato (BARBOSA FILHO et al., 1996), em parcelas de $80 \mathrm{~m}^{2}(10 \times 8 \mathrm{~m})$ distanciadas entre si de $2 \mathrm{~m}$, com cinco repetições. O material foi distribuído a lanço na superfície e incorporado com enxada rotativa. Todas as parcelas receberam por ocasião da semeadura do arroz (cv. Caiapó) $30 \mathrm{~kg} \mathrm{ha}^{-1}$ de $\mathrm{N}$ na forma de sulfato de amônio, $120 \mathrm{~kg} \mathrm{ha}^{-1}$ de $\mathrm{P}_{2} \mathrm{O}_{5}$ na forma de superfosfato triplo, $60 \mathrm{~kg} \mathrm{ha}^{-1}$ de $\mathrm{K}_{2} \mathrm{O}$ na forma de cloreto de potássio e $5,75 \mathrm{~kg} \mathrm{ha}^{-1}$ de $\mathrm{Zn}$ na forma de sulfato de zinco. Em cobertura, foram aplicados 50 $\mathrm{kg} \mathrm{ha}^{-1}$ de $\mathrm{N}$ por volta dos 55 dias após a emergência, quando apareceu o primórdio floral. 
As sementes foram semeadas no espaçamento de $0,40 \mathrm{~cm}$ entre linhas com aproximadamente 70 sementes. $\mathrm{m}^{-1}$. No controle de pragas do solo, foram aplicados $20 \mathrm{~kg} \mathrm{ha}^{-1}$ de Furadan granulado $5 \mathrm{G}$ no sulco de plantio e as ervas daninhas foram eliminadas por meio de capinas manuais. Para o segundo cultivo, o solo foi preparado com duas gradagens e as demais práticas culturais foram as mesmas empregadas para o primeiro cultivo, com exceção da adubação com $\mathrm{Zn}$, que foi feita apenas para o primeiro cultivo.

$\mathrm{Na}$ colheita, determinaram-se a produtividade de grãos, a acumulação de Si na palha, o número de grãos cheios panícula ${ }^{-1}$ e a porcentagem de grãos vazios. A porcentagem de Si na palha foi determinada com o emprego do método da digestão induzida em autoclave, descrito por Elliott e Snyder (1991). Em amostras de solo coletadas em cada parcela após a segunda colheita, extraiu-se o Si solúvel em ácido acético $0,5 \mathrm{~mol} \mathrm{~L}^{-1}$, segundo Snyder (1991), visando a obter informações sobre a capacidade de extração do extrator, em função das doses aplicadas de escória.

A determinação do Si nos extratos foi feita colorimetricamente usando o complexo de molibdato de amônio (SNYDER, 1991). Depois da análise estatística, curvas de resposta foram ajustadas para produtividade de grãos e absorção de Si pelas plantas, em função das doses de escória. Para as variáveis de produtividade de grãos, Si acumulado e concentração de Si na palha, foi adotado o modelo linear com duas tendências, segundo Draper e Smith (1981), assumindo como conhecido o ponto de mudança de tendência $\left(\mathrm{Y}=\mathrm{b}_{0}+\mathrm{b}_{1} \mathrm{x}_{1} \mathrm{~b}_{2} \mathrm{x}_{2}\right)$, em que $b_{0}$ é a interseção das duas tendências.

Os resultados das análises do solo para Si solúvel foram submetidos a análises de variância, regressão e correlação e relacionados às quantidades aplicadas de escória. Na determinação do nível crítico de Si na palha, adotou-se o método de Cate e Nelson (1971).

\section{RESULTADOS E DISCUSSÃO}

\section{Efeitos sobre o solo e a absorção de $\mathrm{Si}$}

A acidez do solo medida pelo $\mathrm{pH}$ e concentração de $\mathrm{H}+\mathrm{Al}$ diminuiu com a aplicação da escória, favorecendo o desenvolvimento da cultura do arroz (Figura 1a, d). Com a aplicação da escória e diminuição da acidez do solo, houve aumento da disponibilidade de Si solúvel, cujo valor no início era de $16 \mathrm{mg} \mathrm{L}^{-1}$ e depois da aplicação da escória, atingiu $60 \mathrm{mg} \mathrm{L}^{-1} \mathrm{em}$ ácido acé- tico $0,5 \mathrm{~mol} \mathrm{~L}^{-1}$ (Figura 1b), favorecendo a sua absorção pelas plantas. Outras conseqüências da aplicação da escória detectadas no solo após o cultivo do arroz foram os aumentos da disponibilidade de fósforo (Figura 1c) e cálcio (Figura 1e) e a elevação da porcentagem de saturação por bases (Figura 1f). Isso refletiu no aumento significativo do número de grãos cheios por panícula e na redução da porcentagem de grãos vazios (Figura 3b,c), justificando os aumentos na produtividade de grãos.

A absorção de Si pelas plantas, avaliada pelo teor e acumulação na palha na colheita, foi positivamente relacionada com a aplicação de escória nos dois anos de cultivo (Figura 2a, b). Nos tratamentos sem adição de escória, os teores de Si na palha variaram de 1,03\% a $1,35 \%$, estando muito abaixo daqueles relatados por Lian (1976), de 5,0\% a 6,0\%, e por Snyder et al. (1986, de $3,0 \%$, considerados como críticos na palha por estarem relacionados com produtividade satisfatória de grãos para o arroz irrigado.

Neste trabalho, utilizando-se o arroz de terras altas, os teores mais elevados de $\mathrm{Si}$ foram de 2,69\% e $2,65 \%$, no primeiro e segundo cultivo, respectivamente, nas parcelas que receberam a dose mais alta de escória (10 t ha ${ }^{-1}$ ) (Figura 2). Aplicando-se o método de Cate e Nelson (1971) para determinação do nível crítico aos dados de produtividade de grãos, estabeleceu-se o nível crítico de 2,25\% de Si na palha, para o arroz de terras altas (Figura 4). As diferenças entre os teores de Si encontradas em plantas de arroz de terras altas no Brasil e irrigadas de outros países são atribuídas às desigualdades no potencial produtivo das cultivares, ao manejo cultural, à diferença do método empregado para análise de Si no tecido vegetal e ao tipo de solo completamente diferente que pode ter interferido na fixação do $\mathrm{Si}$, diminuindo sua disponibilidade (BARBOSA FILHO et al., 2001b).

Considerando a análise de cada ano de cultivo (Figura 4a, 4b), observa-se que embora os teores de Si continuem aumentando com as doses aplicadas de escória, os teores de Si decresceram de um ano agrícola para outro, o que pode ser conseqüência de reações de fixação de íons silicato no solo com o decorrer do tempo. A extração de Si com ácido acético 0,5 mol $\mathrm{L}^{-1}$ foi mais efetiva na remoção desse elemento da solução do solo do que a extração em água (Figura 4a, b), o que está relacionada ao menor pH do ácido acético. Segundo Kato e Owa (1990), a solubilidade do Si no solo aumenta com a diminuição do $\mathrm{pH}$. 

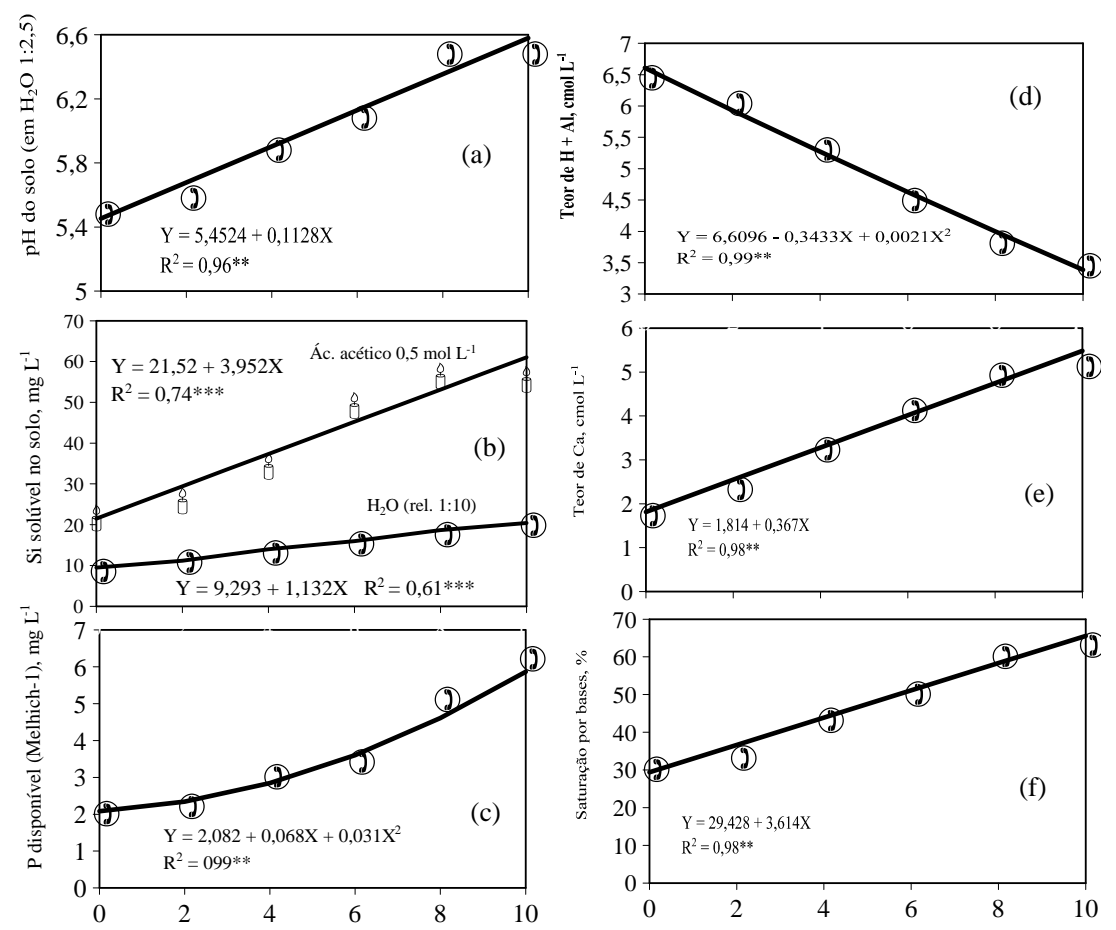

Doses de escória, $\mathrm{t} \mathrm{ha}^{-1}$

FIGURA 1 - Efeito da aplicação de escória em atributos químicos do solo: (a) pH, (b) Si disponível, (c) P disponível, (d) $\mathrm{H}+\mathrm{Al}$, (e) $\mathrm{Ca}^{+2}$ trocável, (f) saturação por bases (V\%), na camada de 0-20 cm de profundidade, após a segunda colheita do arroz.

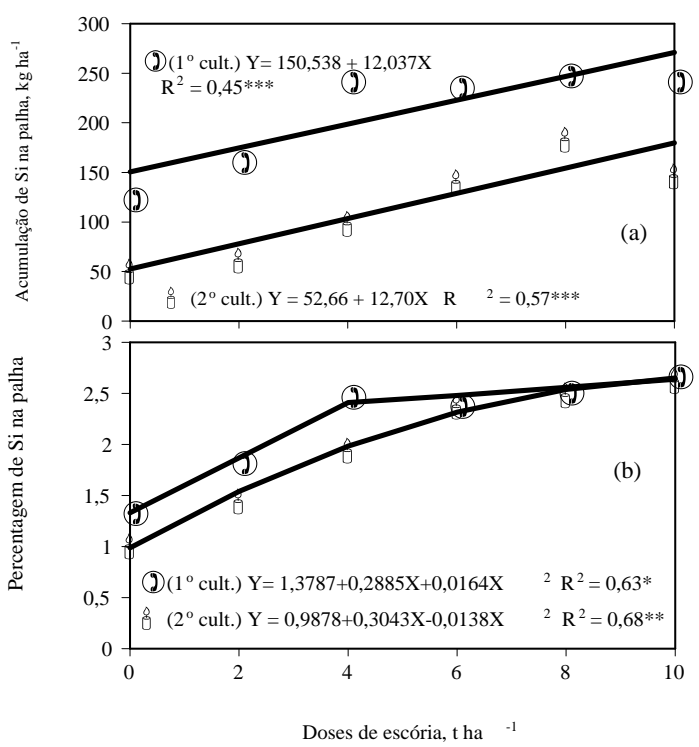

FIGURA 2 - Efeito da aplicação de escória na acumulação de Si (a) e na concentração de Si na palha do arroz (b), no primeiro e no segundo ano de cultivo.

Ciênc. agrotec., Lavras, v. 28, n. 2, p. 323-331, mar./abr., 2004 


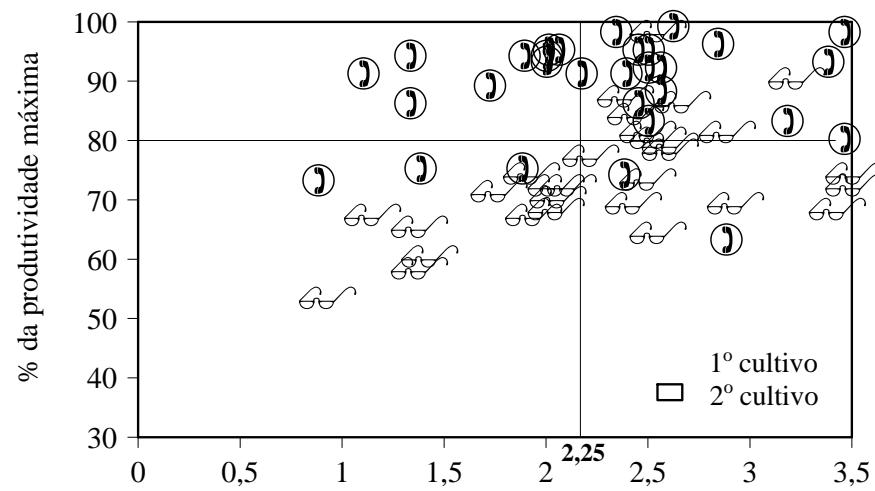

Si na palha, \%

FIGURA 3 - Relação entre Si na palha do arroz na época da colheita e a porcentagem da produtividade máxima de grãos e nível crítico, segundo Cate e Nelson (1971).
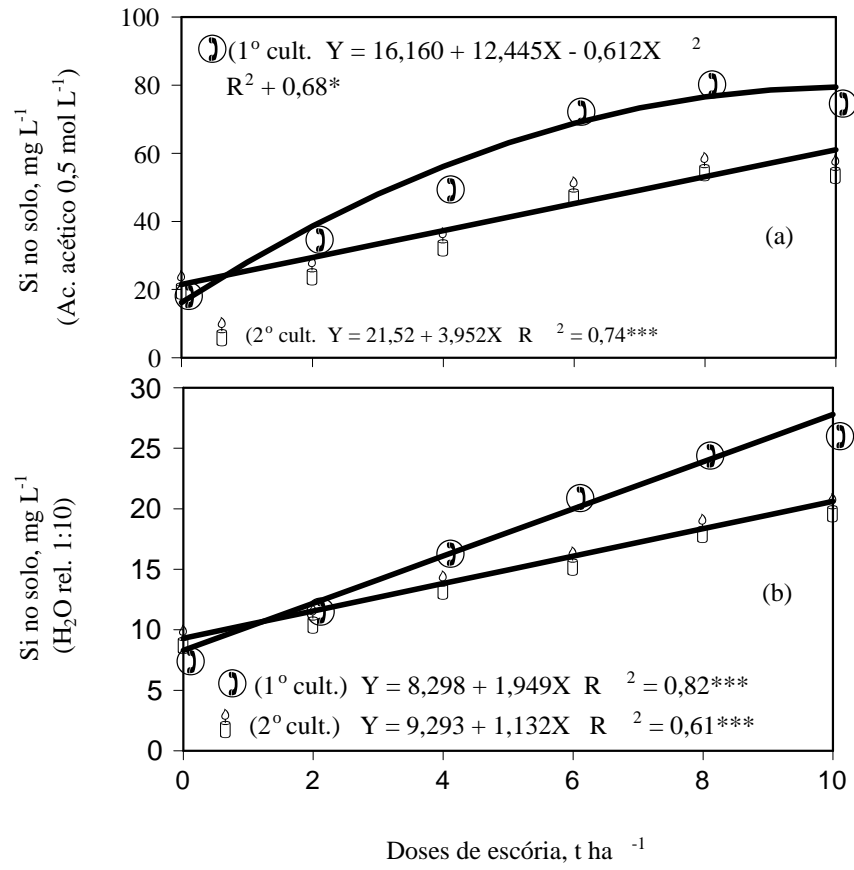

FIGURA 4 - Efeito da aplicação de escória sobre o Si solúvel em ácido acético 0,5 mol L ${ }^{-1}$ (a) e em água (rel. 1:10) (b), em amostras de solo coletadas na camada de 0-20 cm de profundidade, após dois anos de cultivo do arroz. 
As variáveis de porcentagem e acumulação de Si na palha correlacionam-se significativamente entre si e com os extratores empregados, tanto no primeiro (Tabela 1) quanto no segundo ano de cultivo (Tabela 2), demonstrando que tanto as variáveis de plantas quanto os extratores foram capazes de predizer a resposta do arroz em relação ao Si extraído do solo, corroborando os resultados de Barbosa Filho et al. (2001a) observados nos solos orgânicos do sul da Flórida, (EUA), utilizando os mesmos extratores. Quanto às variáveis de produtividade de grãos, as correlações com Si solúvel extraído pelos dois extratores foram significativas e positivas (Tabelas $1 \mathrm{e}$ 2), à exceção do número de grãos vazios no primeiro ano de cultivo (Tabela 1), cuja correlação foi negativa, em razão dos aumentos de produtividade de grãos e número de grãos cheios por panícula observados com o aumento das doses aplicadas de escória
(Figura 5a, c). Os resultados são indicativos de que outros estudos mais abrangentes sobre a utilização de escórias na agricultura devem ser realizados, podendo ser mais uma alternativa para o escoamento deste subproduto.

\section{Efeitos sobre a produtividade de grãos e com- ponentes da produção}

A análise de variância revelou efeito significativo e positivo das doses de escória para produtividade de grãos, tanto no primeiro quanto no segundo cultivo do arroz, enquanto os componentes da produção, número de grãos cheios por panícula e porcentagem de grãos vazios foram afetados pela aplicação da escória apenas no primeiro cultivo (Figura $5 \mathrm{a}, \mathrm{b}, \mathrm{c})$.

TABELA 1 - Coeficientes de correlação e respectivas significâncias estatísticas, pelo teste t, entre as variáveis de solo e planta no primeiro ano de cultivo, levando-se em consideração todos os tratamentos.

\begin{tabular}{|c|c|c|c|c|c|c|}
\hline Variáveis & $\begin{array}{l}\text { Si no solo } \\
\text { (ac. acético } \\
\left.0,5 \text { mol L L }^{-1}\right)\end{array}$ & $\begin{array}{c}\text { Si no solo } \\
\left(\mathrm{H}_{2} \mathrm{O} \text { rel. }\right. \\
1: 10)\end{array}$ & $\begin{array}{c}\text { Acumulação } \\
\text { de Si na } \\
\text { palha }\end{array}$ & $\begin{array}{c}\text { Concentração } \\
\text { de Si na } \\
\text { palha }\end{array}$ & $\begin{array}{c}\mathbf{N}^{\circ} \text { de grãos } \\
\text { cheios por } \\
\text { panícula }\end{array}$ & $\begin{array}{c}\text { Número } \\
\text { de grãos } \\
\text { vazios }\end{array}$ \\
\hline Produtividade de grãos & $0,50 * *$ & $0,55 * *$ & $0,65^{* * *}$ & $0,58 * *$ & $0,12 \mathrm{~ns}$ & $-0,14 \mathrm{~ns}$ \\
\hline Si no solo (ac. acético, 0,5 $\mathrm{mol} \mathrm{L}^{-1}$ ) & & $0,78 * * *$ & $0,54 * *$ & $0,56^{* *}$ & $0,33 \mathrm{~ns}$ & $-0,45^{*}$ \\
\hline Si no solo $\left(\mathrm{H}_{2} \mathrm{O}\right.$ rel. $\left.1: 10\right)$ & & & $0,75^{* * * *}$ & $0,70 * * *$ & $0,51 \mathrm{~ns}$ & $-0,49 * *$ \\
\hline Acumulação de Si na palha & & & & $0,89 * * *$ & $0,35 \mathrm{~ns}$ & $-0,40 *$ \\
\hline Concentração de Si na palha & & & & & $0,39 *$ & $-0,54 * *$ \\
\hline $\mathrm{N}^{\mathrm{o}}$ de grãos cheios por panícula & & & & & & $-0,74 * * *$ \\
\hline
\end{tabular}

$*, * *, * * *$ e ns $=$ Significativos a $5 \%, 1 \%, 0,1 \%$ e não significativo, respectivamente.

TABELA 2 - Coeficientes de correlação e respectivas significâncias estatísticas, pelo teste t, entre as variáveis de solo e planta no segundo ano de cultivo, levando em consideração todos os tratamentos.

\begin{tabular}{|c|c|c|c|c|}
\hline Variáveis & $\begin{array}{c}\text { Si no solo } \\
\left.\text { (ac. acético } 0,5 \mathrm{~mol} \mathrm{~L}^{-1}\right)\end{array}$ & $\begin{array}{c}\text { Si no solo } \\
\left(\mathrm{H}_{2} \mathrm{O} \text { rel. 1:10) }\right.\end{array}$ & $\begin{array}{c}\text { Acumulação } \\
\text { de Si na palha }\end{array}$ & $\begin{array}{l}\text { Concentração de } \\
\text { Si na palha }\end{array}$ \\
\hline Produtividade de grãos & $0,69 * * *$ & $0,56^{* *}$ & $0,60 * * *$ & $0,61 * * *$ \\
\hline Si no solo (ac. acético $0,5 \mathrm{~mol} \mathrm{~L}^{-1}$ ) & & $0,58 * * *$ & $0,67 * * *$ & $0,66^{* * *}$ \\
\hline Si no solo $\left(\mathrm{H}_{2} \mathrm{O}\right.$ rel. $\left.1: 10\right)$ & & & $0,65 * * *$ & $0,68 * * *$ \\
\hline Acumulação de Si na palha & & & & $0,92 * * *$ \\
\hline
\end{tabular}

$* * \mathrm{e}^{* * *}=$ Significativos a $1 \%$ e $0,1 \%$, respectivamente.

Ciênc. agrotec., Lavras, v. 28, n. 2, p. 323-331, mar./abr., 2004 
Pela análise da Figura 5a verifica-se que a cultura do arroz apresentou alta capacidade de resposta à aplicação de escória, com aumentos acentuados nas doses de 2 a $4 \mathrm{t} \mathrm{ha}^{-1}$, atingindo depois uma estabilização na produtividade de grãos.

No primeiro cultivo, a máxima produtividade de grãos $\left(4.840 \mathrm{~kg} \mathrm{ha}^{-1}\right)$ foi atingida na dose de 4,0 $\mathrm{t} \mathrm{ha}^{-1}$ de escória, determinada pela equação $\mathrm{Y}=4.799+$ 1.045X1 - 23,74X2 $\left(\mathrm{R}^{2}=0,98^{* * *}\right)$, sendo a que melhor se ajustou aos dados. Para manter, no segundo cultivo, a produtividade máxima de grãos da primeira safra, seria necessária a aplicação de $6,9 \mathrm{t} \mathrm{ha}^{-1}$ de escória, calculada a partir da equação linear, substituindo-se Y pela produtividade máxima de grãos da primeira safra.
O fato de a escória conter outros nutrientes e exercer ação corretiva na acidez do solo e de como foi delineado o experimento, não há como afirmar que o Si seja a principal causa para o aumento da produtividade de grãos. Outra observação que reforça a hipótese de um efeito mais amplo da escória foi o fato de não ter ocorrido doenças do arroz nos dois anos de cultivo, eliminando, assim, o principal efeito benéfico do $\mathrm{Si}$ que lhe é atribuído na literatura (DATNOFF et al., 1991, 1992; PRABHU et al., 1999), sugerindo que os efeitos da escória deveramse à sua ação corretiva da acidez do solo e aos aumentos da disponibilidade de fósforo e cálcio às plantas.
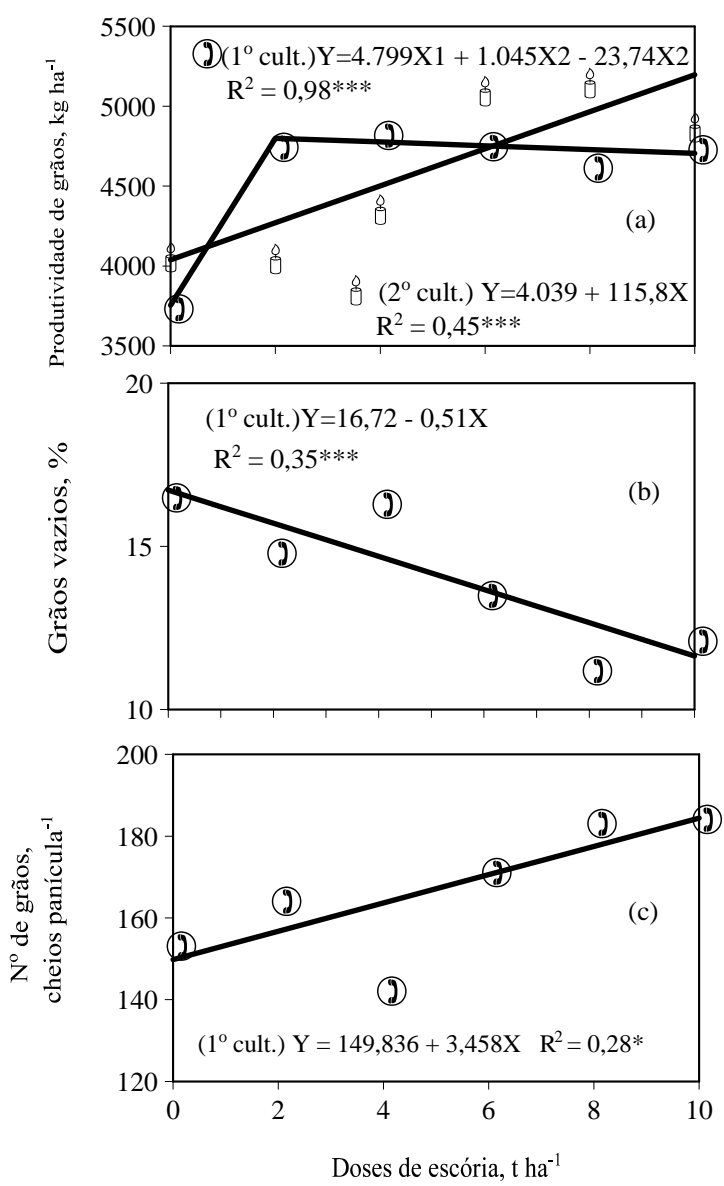

FIGURA 5 - Efeito da aplicação de escória na produtividade de grãos (a), porcentagem de grãos vazios (b) e número de grãos cheios por panícula (c). 


\section{CONCLUSÕES}

A aplicação de escória silicatada promoveu uma ação corretiva do solo, com conseqüente aumento das disponibilidades de silício, fósforo, cálcio trocável e na porcentagem de saturação por bases (V\%).

$\mathrm{O}$ arroz de terras altas respondeu positivamente à aplicação de escória silicatada, em duas safras sucessivas, quanto à absorção de $\mathrm{Si}$ e produtividade de grãos.

O valor de $2,25 \%$ de Si na matéria seca da palha por ocasião da colheita foi o nível crítico mínimo para obtenção de produtividade acima de $80 \%$ da produtividade máxima de grãos de arroz de terras altas.

Os extratores (água e ácido acético $0,5 \mathrm{~mol} \mathrm{~L}^{-1}$ ) usados na estimativa de $\mathrm{Si}$ disponível às plantas correlacionaram positiva e significativamente com o Si absorvido pelas plantas.

\section{REFERÊNCIAS BIBLIOGRÁFICAS}

BARBOSA FILHO, M. P.; SNYDER, G. H.; ELLIOTT, C. L.; DATNOFF, L. E. Assessing silicon sources for plant-available silicon. In: RICE TECHNICAL WORKING GROUP, 36., 1996, San Antonio, Texas. Proceedings... Texas: Texas Agricultural Experiment Station, 1996. p.186.

BARBOSA FILHO, M. P.; SNYDER, G. H.; ELLIOTT, C. L.; DATNOFF, L. E. Evaluation of soil test procedures for determining rice-available silicon. Communications in Soil Science and Plant Analysis, New York, v. 32, n. 11/12, p. 1779-1792, 2001a.

BARBOSA FILHO, M. P.; SNYDER, G. H.; FAGERIA, N. K.; DATNOFF, L. E.; SILVA, O. F. da. Silicato de cálcio como fonte de silício para o arroz de sequeiro. Revista Brasileira de Ciência do Solo, Viçosa, v. 25, n. 2, p. 325-330, 2001 b.

CATE, R. B.; NELSON, L. A. A simple statistical procedure for partitioning soil correlation data into classes. Soil Science Society of America Proceedings, Madison, v. 35, p. 658-660, 1971.

CORREA-VICTORIA, F. J.; DATNOFF, L. E.; WINSLOW, M. D.; OKADA, K.; FRIENSEN, D. K.; SANZ, J. I.; SNYDER, G. H. Deficiência de silica em arroz de sequeiro em solos de savana altamente degradados da Colômbia. II: doenças e qualidade de grão. In: CONFERENNCIA INTERNACIONAL DE ARROZ PARA A AMÉRICA LATINA E O CARIBE, 9., 1994, Goiânia. Anais... Goiânia: EMBRAPA-CNPAF, 1996. v. 2, p. 161. (EMBRAPA-CNPAF. Documentos, 62).
DATNOFF, L. E.; RAID, R. N.; SNYDER, G. H.; JONES, D. B. Effect of calcium silicate on blast and brown spot intensities and yields of rice. Plant Disease, Saint Paul, v. 75, p. 729-732, 1991.

DATNOFF, L. E.; SNYDER, G. H.; DEREN, C. W. Influence of silicon fertilizer grades on blast and brown spot development and on rice yields. Plant Disease, Saint Paul, v. 76, p. 1182-1184, 1992.

DRAPER, N. R.; SMITH, H. Applied regression analysis. 2. ed. New York: John Wiley \& Sons, 1981. $709 \mathrm{p}$.

ELLIOTTI, C. L.; SNYDER, G. H. Autoclave: induced digestion for the colorimetric determination of silicon in rice straw. Journal of Agricultural and Food Chemistry, Washington, v. 39, p. 1118-1119, 1991.

EMPRESA BRASILEIRA DE PESQUISA AGROPECUÁRIA. Centro Nacional de Pesquisa de Solos. Manual de métodos de análise de solo. 2. ed. Rio de Janeiro, 1997. 212 p. (EMBRAPA-CNPS. Documentos, 1).

INSTITUTO BRASILEIRO DE GEOGRAFIA E ESTATÍSTICA. Levantamento sistemático da produção agrícola. Rio de Janeiro, 2002.

INTERNATIONAL FERTILIZER INDUSTRY ASSOCIATION. Rice. Paris, 1992.

KATO, N.; OWA, N. Dissolution mechanism of silicate slag fertilizers in paddy soils. In: INTERNATIONAL CONGRESS OF SOIL SCIENCE, 14., 1990, Kyoto. Proceedings... Kyoto: [s.n.], 1990. v. 4, p. 609-610.

KORNDÖRFER, G. H.; ARANTES, V. A.; CORRÊA, G. F.; SNYDER, G. H. Efeito do silicato de cálcio no teor de silício no solo e na produção de grãos de arroz de sequeiro. Revista Brasileira de Ciência do Solo, Viçosa, v. 23, n. 3, p. 635-641, 1999.

LIAN, S. Silica fertilization of rice. In: FOOD FERTILIZER TECHNOLOGY CENTER. The fertility of paddy soils and fertilizer applications for rice. Taipei, 1976. p. 197-220.

PRABHU, A. S.; BARBOSA FILHO, M. P.; FILIPPI, M. C.; DATNOFF, L. E.; SNYDER, G. H. Silicon from rice disease control perspective in Brazil. In: SILICON IN AGRICULTURE CONFERENCE, 1999, Fort

Ciênc. agrotec., Lavras, v. 28, n. 2, p. 323-331, mar./abr., 2004 
Lauderdale. Proceedings... Gainesville: University of Florida, 1999. v. 1, p. 1-44.

PRABHU, A. S.; BARBOSA FILHO, M. P.; FILIPPI, M. C.; DYNIA, J. F. Influência de fertilização com Si sobre mancha de grãos em arroz. Fitopatologia Brasileira, Brasília, v. 21, p. 405, 1996. Resumo.

ROY, A. C.; ALI, M. Y.; FOX, R. L.; SILVA, J. A Influence of calcium silicate on phosphate solubility and availability in Hawaiian latosols. In: INTERNATIONAL SYMPOSIUM ON SOIL FERTILITY EVALUATION, 1971, New Delhi. Proceedings... New Delhi: [s.n.], 1971. p. 757-768.

SAVANT, N. K.; SNYDER, G. H.; DATNOFF, L. E Silicon management and sustainable rice production.
Advances in Agronomy, New York, v. 58, p. 151-199, 1997.

SNYDER, G. H. Development of a silicon soil test for Histosol-grown rice. Belle Grade: University of Florida, 1991. (EREC Res. Rep. EV1991-2).

SNYDER, G. H.; JONES, D. B.; GASCHO, G. J. Silicon fertilization of rice on Everglades Histosols. Soil Science Society of America Journal, Madison, v. 50, p. 1259-1263, 1986.

SOUZA, E. C. A. de; YASUDA, M. Uso agronômico do termofosfato no Brasil. São Paulo: Fertilizantes Mitsui, 1994. $60 \mathrm{p}$. 